\title{
Morphology-properties relationship on nanocomposite films based on poly(styrene-block-diene-block-styrene) copolymers and silver nanoparticles
}

\author{
L. Peponi ${ }^{*}$, A. Tercjak², L. Martin², I. Mondragon ${ }^{2}$, J. M. Kenny ${ }^{1}$ \\ ${ }^{1}$ Materials Engineering Centre, University of Perugia, Loc. Pentima Bassa, 21, 05100 Terni, Italy \\ 2‘Materials + Technologies' Group, Dpto. Ingeniería Química y M. Ambiente, Escuela Politécnica, Universidad País \\ Vasco/Euskal Herriko Unibertsitatea, Pza. Europa 1, 20018 Donostia-San Sebastián, Spain
}

Received 13 July 2010; accepted in revised form 29 September 2010

\begin{abstract}
A comparative study on the self-assembled nanostructured morphology and the rheological and mechanical properties of four different triblock copolymers, based on poly(styrene-block-butadiene-block-styrene) and poly(styrene-blockisoprene-block-styrene) matrices, and of their respective nanocomposites with $1 \mathrm{wt} \%$ silver nanoparticles, is reported in this work. In order to obtain well-dispersed nanoparticles in the block copolymer matrix, dodecanethiol was used as surfactant, showing good affinity with both nanoparticles and the polystyrene phase of the matrices as predicted by the solubility parameters calculated based on Hoftyzer and Van Krevelen theory. The block copolymer with the highest PS content shows the highest tensile modulus and tensile strength, but also the smallest elongation at break. When silver nanoparticles treated with surfactant were added to the block copolymer matrices, each system studied shows higher mechanical properties due to the good dispersion and the good interface of Ag nanoparticles in the matrices. Furthermore, it has been shown that semiempirical models such as Guth and Gold equation and Halpin-Tsai model can be used to predict the tensile modulus of the analyzed nanocomposites.
\end{abstract}

Keywords: nanocomposites, block copolymer, atomic force microscopy, rheology, mechanical properties

\section{Introduction}

Metal-polymer nanocomposites (MNC) consisting of metallic nanoparticles incorporated into polymers are receiving immense attention in today's research for their potential applications in the fields of catalysis, bioengineering, photonics and electronics [1-3]. The salient features of these nanostructures, the material composition, as well as morphology, dimensions, spacing, and order are of primary significance for the chemical, mechanical, optical and electromagnetic properties they exhibit. Not only nanoparticles give rise to nanocomposite with exceptional properties, but also the nano-orga- nization of the matrix is an important factor to take into account when working with nanocomposite materials. So, the spontaneous formation of nanostructured materials via molecular self-assembly has attracted increasing interest throughout the last decades. Block copolymers, BC, are a prominent example of this class of material as they form a large variety of well-ordered microdomain structures of molecular dimensions [4-7]. BC are longchain molecules built up from different types of monomers, which are grouped in blocks covalently linked to each other. Depending on length, connectivity, the degree of polymerization, mutual interac- 
tions of the different blocks and solvent used, the microdomains can form spheres, cylinders, lamellae, or more complex shapes $[8,9]$.

The molecular packing and the thermodynamically stable microdomain patterns of block copolymers are governed by the positive mixing enthalpy and the low mixing entropy of block segments. Since the covalent bonding between the segments, the systems can not macroscopically phase separate and, in order to minimize the interfacial energy, they adjust themselves in well-defined microdomain patterns $[10,11]$. When the blocks mix endothermically the origin of microphase separation can be attributed to enthalpic effects $[12,13]$. Evidently, the microphase separation of block copolymers affects their rheological behaviour [1416] and mechanical behavior [16-18]. Unusual melt rheological properties of block copolymers such as very high viscosity and elasticity, very high sensitivity to the molecular weight and highly nonNewtonian behaviour even at very low shear rates and high temperature, (i.e. non-terminal behaviour) have been reported in literature [19]. The order-disorder transition Temperature $\left(T_{\mathrm{ODT}}\right)$, also referred to as the microphase separation transition Temperature $\left(T_{\mathrm{MST}}\right)$, which indicates the temperature at which the $\mathrm{BC}$ changes from a homogeneous material to a microphase separated state, is found in literature to be accompanied by gross changes in the rheological properties at low frequencies [19-21].

The unique properties of $\mathrm{BC}$ can be further improved and enlarged, introducing nanosized objects into their mesostructure opening the way to many innovative applications. Combination of both nanosized particles and nanostructured templates can lead to increased quantities of unique and complex nanocomposite materials [22-24].

Nevertheless, the main drawback of nanoparticles, which still limits their wide applications, is related to their high surface energy which implies a high tendency to self-aggregation. Their stabilization in different polymeric matrices has been proven to be one of the most promising strategies to prevent their aggregation and to design and control the properties of the resulting nanocomposites [25].

Surfactants are, usually, amphiphilic organic compounds, which contain both hydrophobic groups (their tails compatible with the polymer) and hydrophilic groups (their heads tethered to the nanoparti- cles) that can lower the surface energy of nanoparticles to prevent their aggregation and to well-disperse them into the polymeric matrix [26]. Moreover, when working with block copolymer matrices, an adequate surfactant should be able to selectively disperse nanoparticles in only one of the blocks through physical or chemical interactions, without altering the chemical structure of the block copolymer matrix. This selectivity is exploited to design the properties of nanoparticle/block copolymer hybrid systems containing well-dispersed nanoparticles [27]. As previously published by our research group [28, 29], when surfactant modified silver nanoparticles are added to poly(styrene- $b$-isoprene- $b$-styrene) as well as to poly(styrene- $b$-butadiene- $b$-styrene), morphological changes can be obtained due to the enlargement of the polystyrene phase. Consequently, the thermal, mechanical and rheological behaviour of the nanocomposites would change with respect to the same properties shown by neat BC. Property enhancement is strongly dependent on the morphology and on the degree of dispersion of the inorganic phase in the polymeric matrix [30].

The main aim of this work is to analyze novel metal-polymer nanocomposites that combine phaseseparated block copolymer domains ordered at nanoscale and nanosized silver particles dispersed with the aid of dodecanethiol (DT) used as surfactant. In particular four different poly(styrene-blockdiene(butadiene or isoprene)-block-styrene) block copolymer matrices (two SBS and two SIS) with different amounts of polystyrene (PS), are compared. Above all, this study focuses on the influence of the addition of $1 \mathrm{wt} \% \mathrm{Ag}$ nanoparticles on the morphology, rheological and mechanical properties of block copolymers. Moreover, two models, Guth and Gold equation [31, 32] and Halpin-Tsai model $[33,35]$ have been used to predict the tensile modulus of the obtained nanocomposites.

\section{Experimental}

\subsection{Materials}

Four different block copolymers, two poly(styrene$b$-butadiene- $b$-styrene) block copolymers and two poly(styrene- $b$-isoprene- $b$-styrene) block copolymers with different amounts of PS block, kindly provided by Kraton Polymers, Kraton Performance Polymers Inc., Amsterdam, Europe, were selected. Values of specific volume of $0.95 \mathrm{~cm}^{3} \cdot \mathrm{g}^{-1}$ were 
used for PS, of $1.1 \mathrm{~cm}^{3} \cdot \mathrm{g}^{-1}$ for PB and $1.25 \mathrm{~cm}^{3} \cdot \mathrm{g}^{-1}$ for PI [36].

Silver nanopowder, P203, was supplied by Cima Nano Tech, Cima NanoTech Inc., Caesarea, Israel. It has a specific surface area of $4.9 \mathrm{~m}^{2} / \mathrm{g}$ and particle size distribution varying from 20 to $70 \mathrm{~nm}$ with evident particle agglomeration. Prior to use it was subjected to thermal treatment to purify the nanoparticles. In fact, the data sheet of the nanoparticles indicates residual processing solvent and impurities and from thermal gravimetric analysis (TGA) (data not shown) $3 \mathrm{wt} \%$ of impurities have been detected; so a thermal treatment at $700^{\circ} \mathrm{C}$ for $1 \mathrm{~h}$ has been performed in air conditions. After this treatment no more impurities were detected by TGA analysis and no evident agglomeration was observed. We consider an elastic modulus of about $80 \mathrm{GPa}$ for the silver nanoparticles. We took as reference the elastic modulus of bulk material considering that the value is closed to the average elastic modulus calculated by Greer et al. [37] for nanoparticles silver thin films.

Previously, we have studied the behavior of nanostructured copolymers when different amounts of silver nanoparticles (from 0 to $7 \mathrm{wt} \%$ ) have been added focusing the attention on the morphological changes of the self-assembled nanostructures [27]. Following these results we have selected $1 \mathrm{wt} \%$, corresponding to $0.10 \mathrm{vol} \%$, as this concentration of silver nanoparticles showed a better dispersion behaviour. Following previous research results on the efficiency of different surfactants on the dispersion of Ag nanoparticles in polymer matrices [29] we have selected dodecanethiol, DT, from SigmaAldrich $^{\circledR}$, Spain, as surfactant in this research. Pure toluene was used as solvent.

\subsection{Sample preparation}

Metallic-organic hybrid films have been obtained sonicating silver nanoparticles in toluene solution for $1.5 \mathrm{~h}$ with a microprocessor sonicator $750 \mathrm{~W}$, Vibracell 75043 from Bioblock Scientific, Fisher Scientific SAS, France, with amplitude of $25 \%$. Another $1 \mathrm{~h}$ of sonication was necessary, when dodecanethiol was added to the Ag solution (optimized weight ratio of $1: 1$ respect to Ag nanoparticles [18]) in order to obtain Ag/DT well dispersed suspension. Finally nanocomposites were obtained, after the addition of the $\mathrm{BC}$ at the suspension and sonicating for further $3 \mathrm{~h}$. The final solution was cast on a glass support. The solvent was evaporated for $24 \mathrm{~h}$ at room temperature.

Solution processing is the typical route to obtain and study the morphologies of nanostructured block copolymers. This processing route can lead to the formation of pores on the film surface that can alter or destroy the nanostructuration. Sometimes it is also possible to obtain solvent tracks on the surface due to a wrong evaporation process. For this reason we have optimized the solution processing of these materials in our long and well documented research on block copolymers. In particular we have chosen an adequate solvent with relatively low vapour pressure such as toluene, and adequate processing conditions (such as to cover the film cast with an aluminium foil and evaporating the solvent slowly under ambient conditions for $24 \mathrm{~h}$ ) to avoid pores in the surface. No pores were observed by visual and microscopic inspection on the films produced.

The self-organization of the block copolymer matrices did not require special annealing conditions (similar nanostructured morphologies have been obtained at room temperature and after annealing at $110^{\circ} \mathrm{C}$ ). Samples of different thickness have been prepared for the AFM analysis (about $300 \mathrm{~nm}$ ) and for rheological and mechanical analysis $(300 \mu \mathrm{m})$. The same procedure was used to obtain neat block copolymers thin films, which were labelled as L1, L2, L3 and L4, respectively, in Table 1. Nanocomposites with $0.10 \mathrm{vol} \% \mathrm{Ag}$ nanoparticles treated with dodecanethiol are named N1, N2, N3 and N4, respectively. As reported on Table 3, L(1/4)+DT represents the block copolymer with $1 \mathrm{wt} \% \mathrm{DT}$, which is the same weight concentration of surfactant added in the nanocomposite formulations. The last sample, $\mathrm{N}(1 / 4) \mathrm{ws}$, indicates the nanocomposite obtained without surfactant.

Table 1. Main characteristics of the different BC studied

\begin{tabular}{|l|c|c|c|c|c|}
\hline \multicolumn{1}{|c|}{ Materials } & $\mathbf{M}_{\mathbf{n}}$ & $\mathbf{P D}$ & $\mathbf{P S}[\mathbf{w t} \mathbf{\%}]$ & $\mathbf{T}_{\mathbf{g}}\left[{ }^{\circ} \mathbf{C}\right]$ & $\mathbf{T}_{\text {ODT }}\left[{ }^{\circ} \mathbf{C}\right]$ \\
\hline SBS D1493-L1 & 60000 & 1.8 & 75 & 110 & 200 \\
\hline SBS D1101 - L2 & 56500 & 1.6 & 31 & 95 & 149 \\
\hline SIS D1161 - L3 & 81200 & 1.7 & 15 & 90 & 132 \\
\hline SIS D1165 - L4 & 58200 & 1.5 & 30 & 95 & 152 \\
\hline
\end{tabular}




\subsection{Physico-chemical analysis}

Gel permeation chromatography, GPC, tests were performed in Perkin-Elmer LC-235, Perkin Elmer Inc. Spain, equipment with a UV detector set at $245 \mathrm{~nm}$ and a refractive index detector LC-30 RI. The mobile phase was tetrahydrofuran at a flow rate of $1 \mathrm{ml} / \mathrm{min}$. Number average molecular weights $\left(M_{\mathrm{n}}\right)$ and the polydispersity index (PD) were calculated using a universal calibration method with polystyrene standards. A Milton Roy Spectronic Genesys 5 UV spectrophotometer, Spectronic Genesys 5 spectrophotometer, Spain, was used to calculate the critical surfactant concentration necessary to optimally cover the external surface of $\mathrm{Ag}$ nanoparticles that, as reported elsewhere [18], corresponds to an $\mathrm{Ag} / \mathrm{DT}$ wt ratio of 1 .

\subsection{Morphological analysis}

The morphological features of both neat $\mathrm{BC}$ and the respective nanocomposite films were investigated using atomic force microscopy (AFM) operating in tapping mode with a scanning probe microscope (Nanoscope IIIa, Multimode TM from Digital Instruments, Santa Barbara, USA) equipped with an integrated silicon tip/cantilever having a resonance frequency $\sim 300 \mathrm{kHz}$, from the same manufacturer. Height and phase images were obtained under ambient conditions with typical scan speed of $0.5-$ 1 line/s, using a scan head with a maximum range of $16 \mu \mathrm{m} \times 16 \mu \mathrm{m}$. Field Emission Scanning Electron Microscopy, FE-SEM, ZEISS SUPRA 25, Carl Zeiss SMT AG, Germany has been used also for the morphological characterization.

\subsection{Thermal analysis}

Differential Scanning Calorimetry, DSC, measurements were performed with a Mettler Toledo DSC822 calorimeter, (Mettler Toledo Int. Inc., Spain) calibrated with high purity indium. All experiments were conducted under a nitrogen flow of $20 \mathrm{ml} \cdot \mathrm{min}^{-1}$, using 7-10 $\mathrm{mg}$ samples in closed aluminium pans, in a temperature range from 30 to $150^{\circ} \mathrm{C}$ with a rate of $10^{\circ} \mathrm{C} / \mathrm{min}$, using the cycle heating-cooling-heating. The second heating scan is taken into account to calculate the glass transition temperature $\left(T_{\mathrm{g}}\right)$ of the matrices.

Thermogravimetric analysis (TGA) was performed using a Seiko Exstar 6000 TGA (Seiko Instruments Inc, Japan) quartz rod microbalance in nitrogen and air atmosphere at a heating rate of $10^{\circ} \mathrm{C} / \mathrm{min}$. Thermograms were recorder from room temperature to $900^{\circ} \mathrm{C}$. Sample of about $10 \mathrm{mg}$ were used in order to verify the purity of the silver nanoparticles.

\subsection{Rheological tests}

An Advanced Rheometrics Expansion System, Ares, Rheometric Scientific Inc., USA with parallel plates of $25 \mathrm{~mm}$ diameter was used with a gap between the plates around $1 \mathrm{~mm}$. Three different types of experiments were performed: dynamic temperature ramps, dynamic strain sweeps and dynamic frequency sweeps. For the viscoelastic measurements, the samples were tested at $110^{\circ} \mathrm{C}$, which is above the $T_{\mathrm{g}}$ of both blocks of the block copolymer. Moreover, dynamic strain sweep tests at a constant frequency were used to find the linear viscoelastic region in which storage modulus $G^{\prime}$ and loss modulus $G^{\prime \prime}$ were independent of the strain amplitude. In particular, after the strain sweep tests at $110^{\circ} \mathrm{C}$, the linear viscoelastic regime was obtained when the strain amplitude was 0.8. Consequently, isochronal dynamic temperature ramp tests were performed from 110 to $200^{\circ} \mathrm{C}$ at a heating rate of $5^{\circ} \mathrm{C} \cdot \mathrm{min}^{-1}$ and at a frequency of $6.28 \mathrm{rad} \cdot \mathrm{s}^{-1}$. Data were collected and analyzed using the equipment software. Taking the sensibility of the rheometer into account, the error of the value of the storage and loss moduli in each data point was $\pm 3 \%$. The transducer operating range was set to $0.2-200$ or $0.2-2000 \mathrm{~g} \cdot \mathrm{cm}$ depending on the measured torque values. The measurements were performed on 5 samples for each different system. It should be pointed out that there was not difference among the morphologies generated at room temperature and at $110^{\circ}$. In fact, although the polymer was above the $T_{\mathrm{g}}$ of both block copolymers, the morphology remained constant for different annealing times for all the investigated systems. This behaviour was deeply analyzed in previous research $[28,29]$ and attributed to the strong segregation regime of the system under these conditions.

\subsection{Mechanical tests}

In order to study the tensile modulus of the metallic-organic hybrid films, tensile tests were carried out at room temperature using a Minimat 2000 Miniature Materials Tester, Rheometric Scientific Inc., USA. The measurements were performed on 
10 dog-bone shaped samples for each different system. The specimens have been prepared cutting the cast film with a gauge length of $5 \mathrm{~mm}$ by using an Abrasive Cutting Labut 1010 of Benetec Ltd (UK). The tensile modulus was calculated at a cross-head rate of $0.5 \mathrm{~mm} / \mathrm{min}$. Data were collected and analyzed using Rheometric Scientific Minimat Main software. On the other hand, to calculate tensile strength and elongation at break, tensile testing of dog-bone shaped specimens was performed using a universal tensile machine Instron, model 4206, Instron, USA, at a cross-head rate of $50 \mathrm{~mm} / \mathrm{min}$ at room temperature. These two different tests were necessary, because of the high elongation at break of thermoplastic elastomers, which could not be measured by the Minimat alone. Metallic-organic hybrid films with a gauge length of $5 \mathrm{~mm}$ were tested.

\section{Results and discussion}

Four different block copolymers have been analyzed in this work. Table 1 shows their main characteristics in terms of PS content (indicated by Kraton Polymer), the number average molecular weight $\left(M_{\mathrm{n}}\right)$ and the polydispersity index (PI) of each BC, measured by GPC and the $T_{\mathrm{g}}$ of the PS block obtained by DSC. Taking into account the density values for the PS and the PI reported in literature, [38], the solubility parameters calculated based on the Hoftyzer and Van Krevelen theory [39] for each block of the four BC have been reported on Table 2 . Due to the high surface energy of the silver nanoparticles, and to their tendency to form aggregates, in order to obtain well-dispersed silver nanoparticles in the $\mathrm{BC}$ matrix, dodecanethiol was used as surfactant to obtain well-disperse $1 \mathrm{wt} \% \mathrm{Ag} / \mathrm{DT}$ nanocomposites corresponding to $0.10 \mathrm{vol} \% \mathrm{Ag}$. The DT solubility parameter, also calculated based on the Hoftyzer and Van Krevelen theory, is 19.10 very close to the PS one. This fact indicates the good affinity between the dodecanethiol and the PS phase. It is worth to note that the solubility parameters shown in Table 2 confirm that dodecanethioltreated silver nanoparticles are dispersed in the PS block of the block copolymer matrix, for each BC. Rheological results allow to emphasize two main aspects. First, though not shown, the linear viscoelastic response of both SIS and SBS block copolymer matrices in $\mathrm{Ag} / \mathrm{DT} / \mathrm{SIS}$ or $\mathrm{Ag} / \mathrm{DT} / \mathrm{SBS}$
Table 2. Solubility parameters calculated for the four different block copolymers

\begin{tabular}{|l|c|c|}
\hline \multicolumn{1}{|c|}{ Materials } & $\boldsymbol{\delta}(\mathbf{P S})$ & $\boldsymbol{\delta}(\mathbf{P B} / \mathbf{P I})$ \\
\hline SBS D1493 & 18.99 & 17.49 \\
\hline SBS D1101 & 19.08 & 17.42 \\
\hline SIS D1161 & 18.99 & 17.62 \\
\hline SIS D1165 & 18.90 & 17.50 \\
\hline
\end{tabular}

nanocomposites was identified using low-frequency values. Thereafter, the temperature dependency of both storage and loss moduli above the $T_{\mathrm{g}}$ of PS-block for the Ag/DT/SIS and Ag/DT/SBS nanocomposite materials was evaluated.

Basically, homogeneous polymer melts follow typical terminal behaviour, that is, $G^{\prime} \sim \omega_{2}$ and $G^{\prime \prime} \sim \omega_{1}$, as the frequency approaches very small values $[18$, 28]. When a transition, such as a phase separation occurs, a deviation from the terminal behaviour, typically the exponents of frequency in their relation with moduli become smaller. According to the thermal analysis for neat L4 SIS block copolymer, the first transition, around $95^{\circ} \mathrm{C}$, indicates the $T_{\mathrm{g}}$ of PS block while the second one, around $135^{\circ} \mathrm{C}$, can be attributed to an order-disorder transition temperature $\left(T_{\mathrm{ODT}}\right)$. This fact is confirmed by the theoretical value of $T_{\text {ODT }}$ calculated by iteration among the empirical Equation (1) for the interaction parameter $\varphi$ determined by references $[18,36]$ :

$\varphi=-900+\frac{750000}{T_{\mathrm{ODT}}}$

and Equation (2) for $\chi N$, being $\chi$ the Flory-Huggins interaction parameter and $N$ the polymerization degree [36], through:

$\chi N=\varphi\left(M_{\mathrm{w}, \mathrm{PS}} \nu_{\mathrm{PS}}+M_{\mathrm{w}, \mathrm{PI} / \mathrm{PB}} \nu_{\mathrm{PI} / \mathrm{PB}}\right)$

where $M_{\mathrm{w}, \mathrm{PS}}$ and $M_{\mathrm{w}, \mathrm{PI} / \mathrm{PB}}$ corresponds to the molecular weight of the PS and PI/PB blocks, $v_{\mathrm{PS}}$ and $v_{\mathrm{PI} / \mathrm{PB}}$ are the specific volumes of PS and PI/PB respectively. Table 1 reports $T_{\mathrm{ODT}}$ values obtained for the different block copolymers studied. Moreover, in order to confirm these transitions, a morphological AFM analysis of the neat $\mathrm{BC}$ annealed at different temperatures has been previously reported $[28,29]$. In fact, it is worth to note that self-assembled nanostructures of the block copolymer matrix retain its cylindrical structure for different annealing times and temperatures. The $\mathrm{BC}$ nanostructure starts to lose its order after the sample has been annealed for $8 \mathrm{~h}$ at $135^{\circ} \mathrm{C}$. These results are con- 

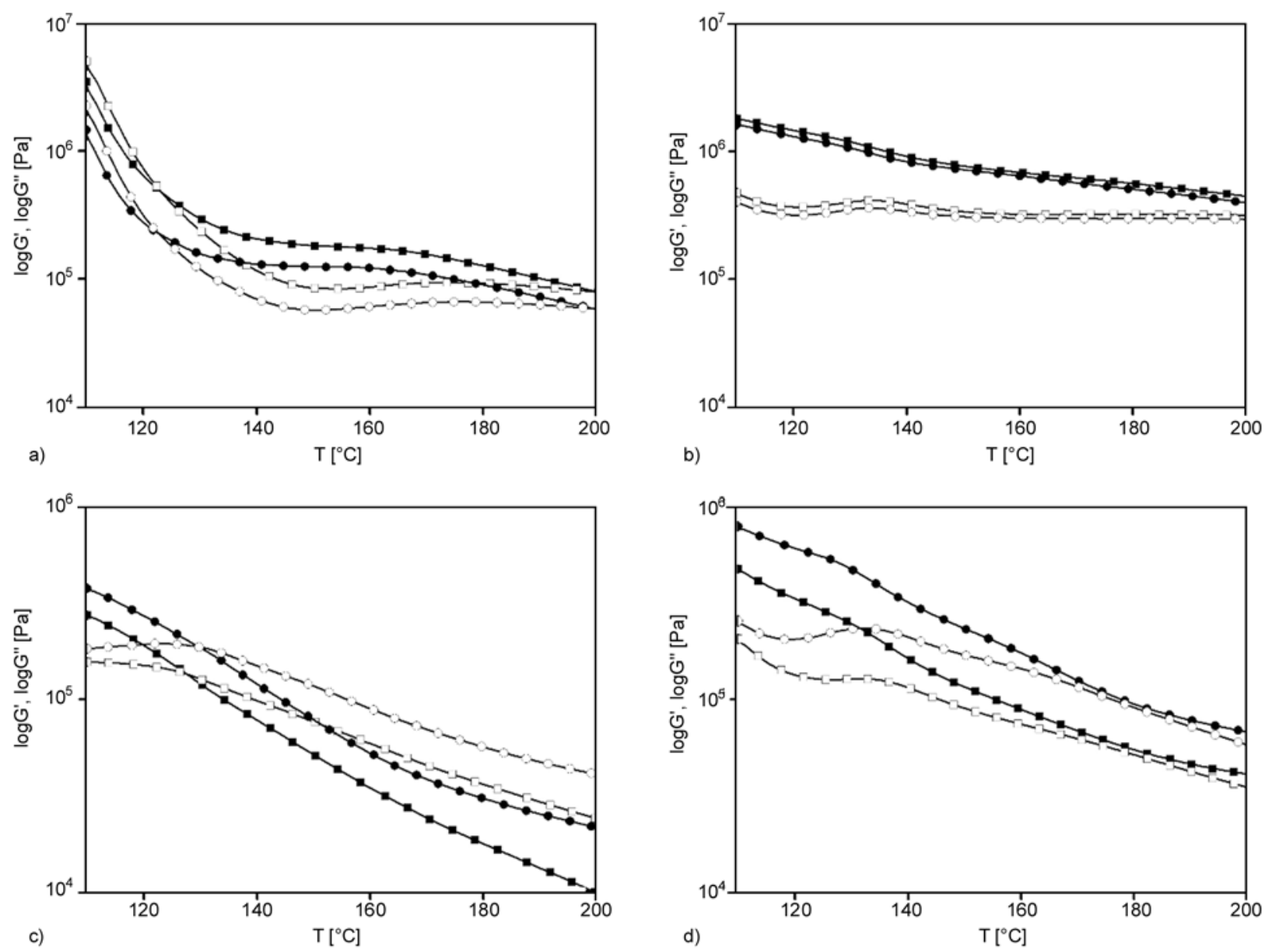

Figure 1. Isochronal dynamic temperature ramps for block copolymers $(\circ)$ and their respective nanocomposites $(\square)$ in terms of $G^{\prime}$ (filled) and $G^{\prime \prime}$ (unfilled): (a) L1, N1, (b) L2, N2, (c) L3, N3, (d) L4, N4

firmed by rheological tests, reported in Figure 1. In particular, Figure 1a reports isochronal dynamic temperature ramps of storage and loss moduli for neat L1 and N1. L1 shows a different behaviour with respect to the other BC systems. The curve of $\mathrm{L} 1$ is the steepest because of the higher value of $T_{\mathrm{g}}$ of PS block of the four block copolymers, as emerged also from thermal analysis. According with the highest $T_{\mathrm{ODT}}$ of the SBS matrix theoretically calculated, also the second transition, referred to the order-disorder transition, takes place at higher temperature respect to the other block copolymers studied. In Figures $1 \mathrm{~b}-1 \mathrm{~d}$ the isochronal dynamic temperature ramps for L2 and N2, L3 and N3, L4 and $\mathrm{N} 4$, respectively, are reported. The transition obtained in the rheological tests around $135^{\circ} \mathrm{C}$ for L4, abrupt fall of $G^{\prime}$ plot and a maximum in $G^{\prime \prime}$ plot, can be attributed to an order-disorder transition, which has been already reported in literature for a diblock poly(styrene- $b$-isoprene) copolymer [40, 41]. While L2 and L4 show very similar rheological behaviour, for L3, a SIS block copolymer with smaller content of PS than the others, the order-disorder transition takes place at temperature lower than $135^{\circ} \mathrm{C}$, where the fall of $G^{\prime}$ plot and the $G^{\prime \prime}$ maximum are obtained. The obtained results are in good agreement with the chemical compositions of the BC matrix. Higher amount of PS leads to higher values of the storage and loss moduli. In the case of $\mathrm{L} 1$ and $\mathrm{N} 1$ the shear thinning allows discrimination between the samples, thus confirming the different behaviour with the increase of PS in the $\mathrm{BC}$ matrix. Moreover, taking into account the behaviour of all nanocomposites, it is worth to note a small transition at about $125^{\circ} \mathrm{C}$, which can be attributed to the decomposition temperature of the silver/dodecyl mercaptide, as reported elsewhere [42].

Due to the dramatic differences in viscoelastic response between the ordered phases in $\mathrm{BC}$ melts, rheological measurements have become a valuable tool to probe morphological changes. Figures $2 \mathrm{a}-$ $2 \mathrm{~d}$ reports the dynamic frequency sweeps for neat 

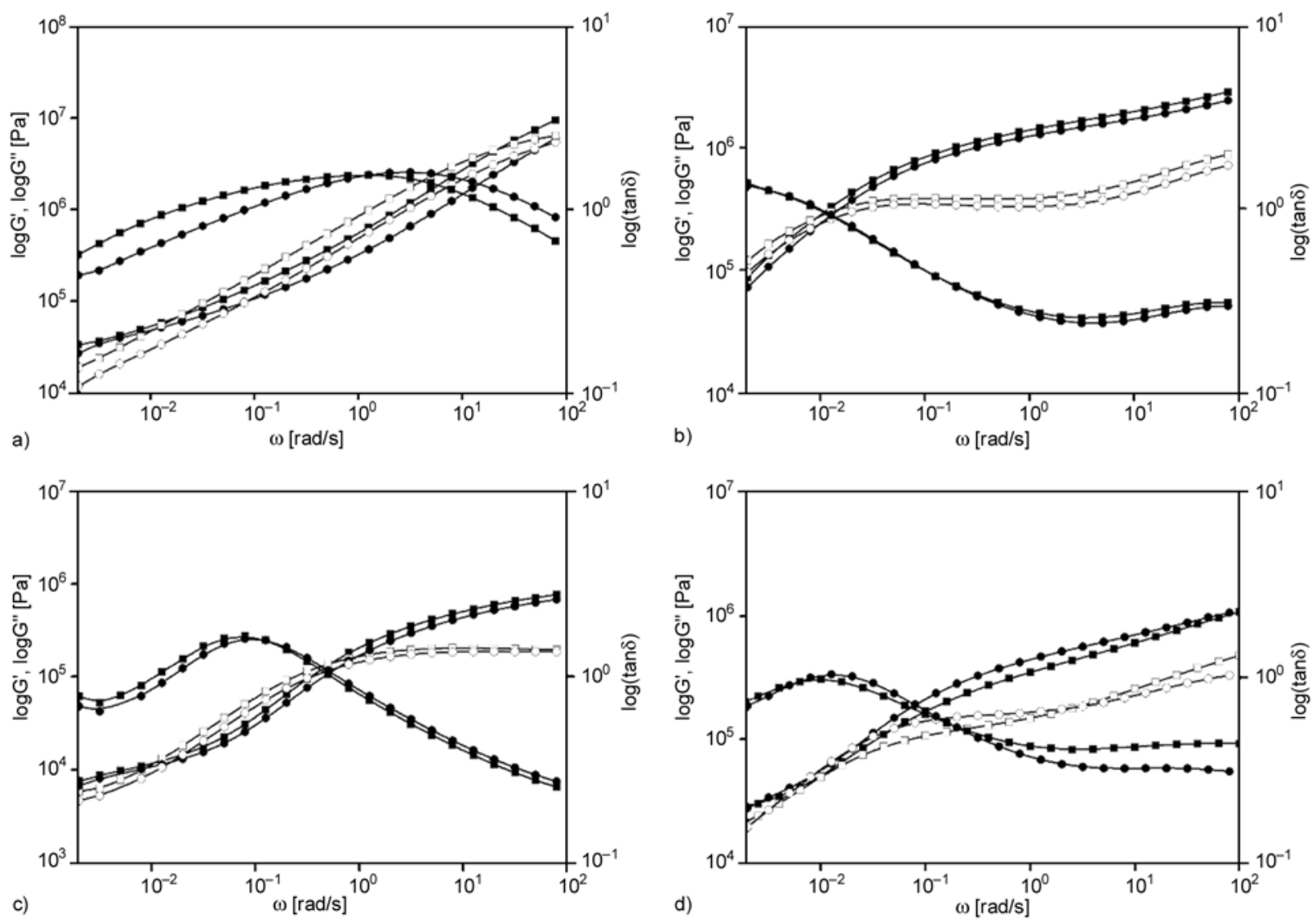

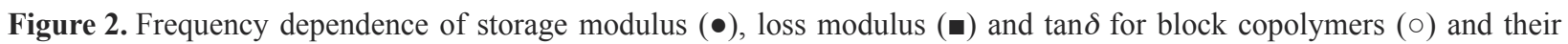
respective nanocomposites ( $\square$ ). (a) L1, N1, (b) L2, N2, (c) L3, N3, and (d) L4, N4. Neat block copolymers are characterized $(\bullet)$, while nanocomposites $(\square)$.

$\mathrm{BC}$ and their corresponding nanocomposites. A crossover of $G^{\prime}(\omega)$ and $G^{\prime \prime}(\omega)$ is evident at different characteristic frequencies for each system. In case of L2-N2 and L4-N4, where the PS content in BC matrix is around $30 \mathrm{wt} \%$, no second crossover of $G^{\prime}(\omega)$ and $G^{\prime \prime}(\omega)$ has been detected. Moreover, only for L4-N4 system, a variation in the power law of $\mathrm{BC}$ with respect to the $\mathrm{NC}$ is observed, which reflects a morphological change. In fact, the power law behaviour, changes from 0.3 in the case of neat $\mathrm{BC}$, consistent with the viscoelastic response of hexagonally closely packed cylindrically ordered structure, to 0.5 that corresponds to a lamellar structure [43]. This morphological change can be confirmed by AFM images, reported in Figure 3d. In fact, in order to get further information on phase separation and on the successful dispersion of $\mathrm{Ag} / \mathrm{DT}$ nanoparticles in the PS phase of the block copolymer, transparent hybrid metal/polymer thin films obtained from the sonicated mercaptide/polymer solutions were analyzed by AFM. Figures 3a$3 \mathrm{~d}$ shows TM-AFM height and phase images, obtained in moderate tapping conditions, for the four neat copolymers and their respective nanocomposites with $0.10 \mathrm{vol} \% \mathrm{Ag}$ nanoparticles. Two main aspects can be evidenced from this analysis. First, it is possible to obtain ordered nanostructures when $\mathrm{Ag} / \mathrm{DT}$ nanoparticles are added to the $\mathrm{BC}$ matrix, and second, morphological changes on the selfassembled nanostructures of the $\mathrm{BC}$ matrix can occur in the respective nanocomposites. For the system L1-N1, reported in Figure 3a, the TM-AFM images show that, although a well defined ordered nanostructure was not detected for the neat $\mathrm{BC}$, the addition of $\mathrm{Ag} / \mathrm{DT}$ nanoparticles does not produce morphological changes (island-like) on the microstructure of $\mathrm{BC}$ matrix and the nanocomposite maintains a similar morphology to that for neat $\mathrm{BC}$. A different situation can be observed for the system L2-N2, reported in Figure 3b. First it can be pointed out that neat L2 shows an ordered cylindrical morphology parallel to the free surface with dimensions of about $20 \mathrm{~nm}$. When DT coated silver nanoparticles are added to the matrix, the ability of this nano- 


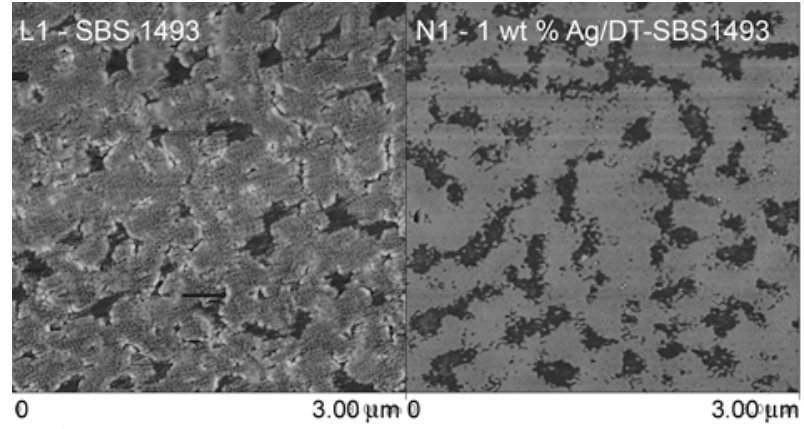

a)

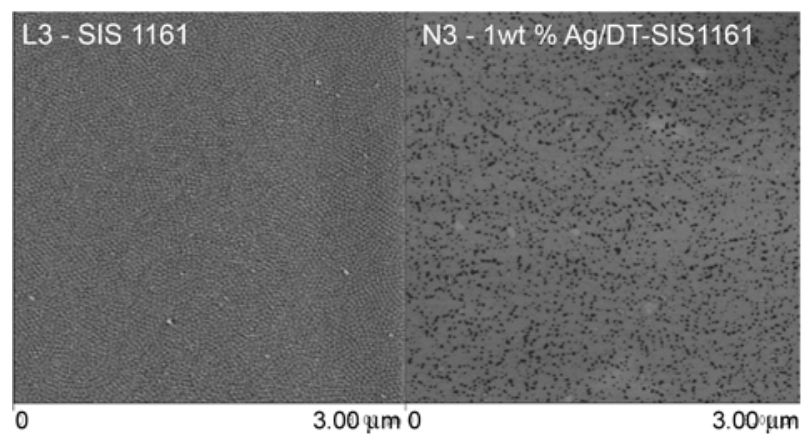

c)

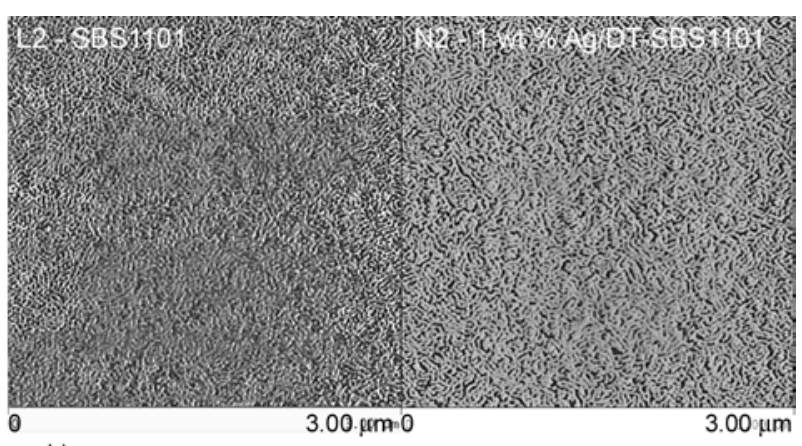

b)

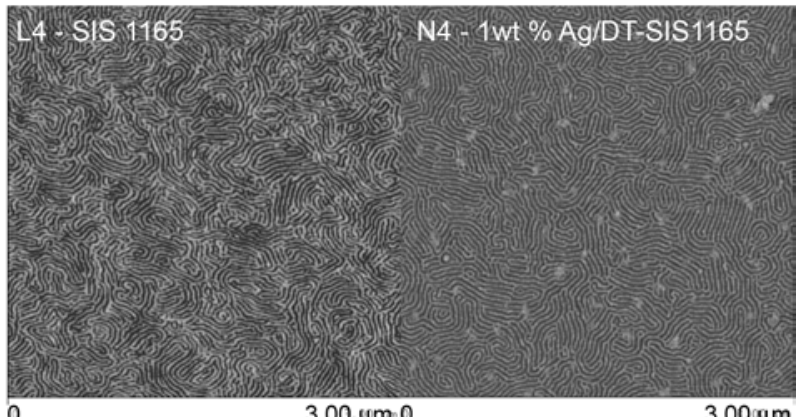

d)

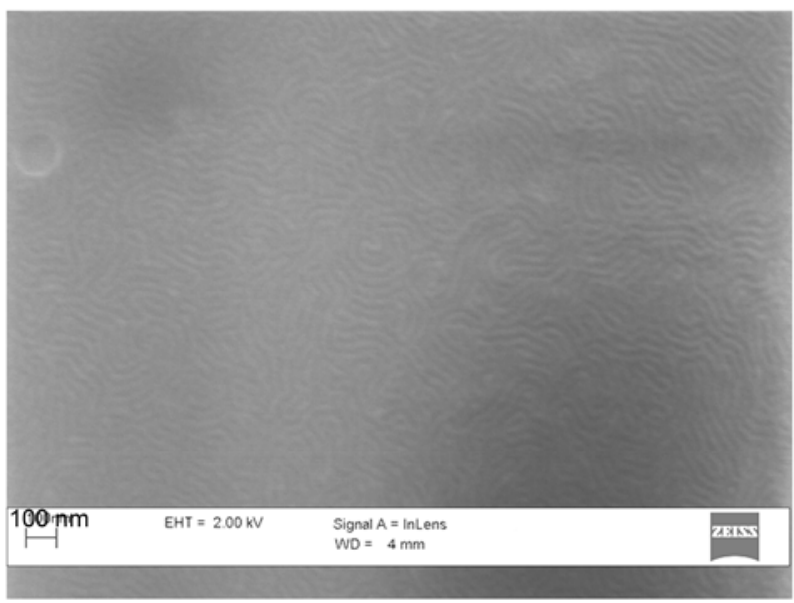

e)

Figure 3. TM-AFM phase images for block copolymers and their respective nanocomposites: (a) L1, N1, (b) L2, N2, (c) L3, N3, (d) L4, N4, (e) L4 FE-SEM micrograph

structured heterogeneous polymer to self-assemble into cylindrical ordered nanostructure is retained. Also in N2 most of the PS cylindrical domains appear oriented parallel to the free surface. But, in this case, the addition of $\mathrm{Ag} / \mathrm{DT}$ nanoparticles leads to an increase of the dimensions of the PS cylinders (about $30 \mathrm{~nm}$ ). This fact confirms that the addition of Ag/DT nanoparticles in the block copolymer matrix enlarges the PS phase, in agreement to the solubility parameters values, and to the interactions noted by thermal analysis between Ag/DT mercaptide and the PS block of the block copolymer. In Figure 3c, for L3 and N3 films a different behaviour is observed. While L3 shows spherical ordered nanostructures, when 0.10 vol $\%$ Ag nanoparticles treated with DT are added to the block copolymer matrix, disordered morphology is obtained. Moreover, in the N3 TM-AFM height and phase images, small aggregations of silver nanoparticles can be detected. These facts can be explained taking into account the PS content in the L3 matrix. In fact, L3 is the block copolymer that has the lowest content of PS respect to the other BC used in this work. It only contains $15 \mathrm{wt} \%$ of PS, thus demonstrating that the small PS microphase of the copolymer, cannot host all the Ag nanoparticles which correspond to $0.10 \mathrm{vol} \%$ of the total amount of copolymer. 
A deeper morphological study of the last system, L4-N4 (Figure 3d), has been reported in a previous publication [29]. Here, it is worth noting that for L4, a cylindrical nanostructure is detected, confirming the microphase separation of PS blocks. Most PS cylindrical domains seem to be oriented parallel to the free surface with a period of about $20 \mathrm{~nm}$. When 0.10 vol\% $\mathrm{Ag}$ nanoparticles treated with DT are added, the nanostructure switches from ordered cylinders for neat BC to a lamellar structure characterized by a interlamellar periodicity of both polymeric phases of about $24-28 \mathrm{~nm}$. The morphological change confirms the enlargement of the PS phase as a consequence of the good confinement of $\mathrm{Ag} / \mathrm{DT}$ nanoparticles on this phase. The same morphological change has been detected previously by rheological tests at low frequencies. In order to compare the self-assembled nanostructures obtained with different techniques Figure 3e shows the FE-SEM analysis of L4. The AFM and FE-SEM images are comparable and even if in the FE-SEM image it is not possible to distinguish the typical AFM phase contrast (soft-dark contrast in the AFM phase images depending on the different phase of the block copolymer) it is possible to detect the same cylindrical nanostructured morphology. In particular, it is well known that homogeneous polymer melts follow a typical terminal behaviour, that is, $G^{\prime}$ is proportional to $\omega^{2}$ and $G^{\prime \prime}$ is proportional to $\omega$, as the frequency approaches very small values. When a transition in a material, such as a phase separation, occurs, a deviation from the terminal behaviour is observed. Typically a smaller exponent in the frequency appears in the relationship $G-\omega$. So, in ordered systems like our nanostructured block

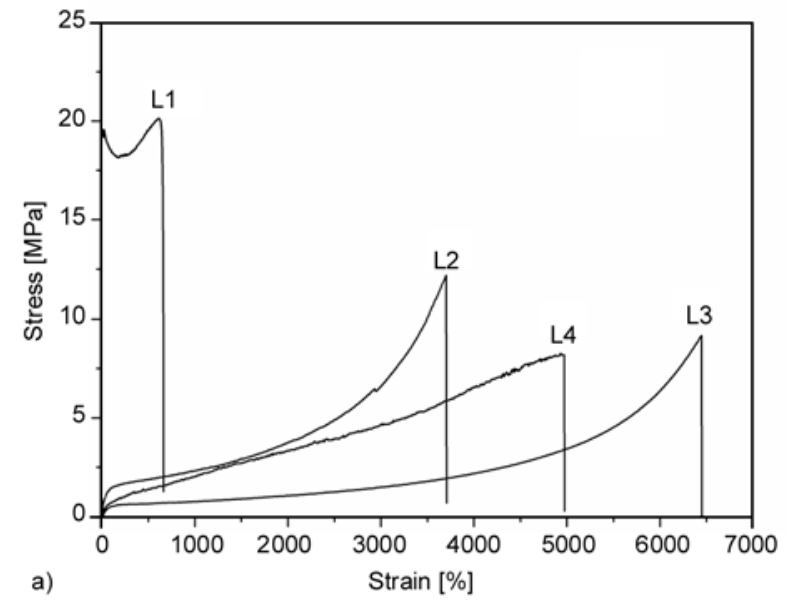

copolymers, the slope of the $G^{\prime}-\omega$ and $G^{\prime \prime}-\omega$ curves at low frequency indicates the different morphologies of the self-assembled nanostructure. So, a slope of 0.3 for both curves corresponds to cylindrical morphologies, while a slope of 0.5 corresponds to lamellar morphologies.

So summarizing the morphological analysis, we must distinguish two different facts. The first one relates to the different morphologies of the four block copolymers studied (Figures 3a-3d, left side). The first one (Figure 3a) shows a poor nanostructuration, the second one (Figure $3 b$ ) shows a typical cylindrical structure [40, 41], the third one (Figure 3c) shows a typical spherical structure and, probably, the less clear morphology is shown by Figure $3 \mathrm{~d}$. Following our experience and previous publications by the main research groups working on this topic $[12,13]$, Figure $3 d$ corresponds to a cylindrical structure parallel to the free surface. After the addition of the silver nanoparticles (see right side of Figures 3a-3d) all the samples show some little morphological changes with no nanostructure transition except for the L4-N4 system (Figure 3d). By comparison of the left and right sides of Figure $3 d$ a slight enlargement of the domains - in length and width - can be detected. The longer domains are compatible with the change to a lamellar structure while the larger domains of the PS phase depend on the interaction of the nanoparticles with the neat matrix as already reported.

It is interesting to note that the morphology of BC and the good dispersion of nanoparticles in their nanocomposites affect not only the rheological behavior but also their mechanical properties. In Figures $4 \mathrm{a}, 4 \mathrm{~b}$ the stress-strain curves are reported

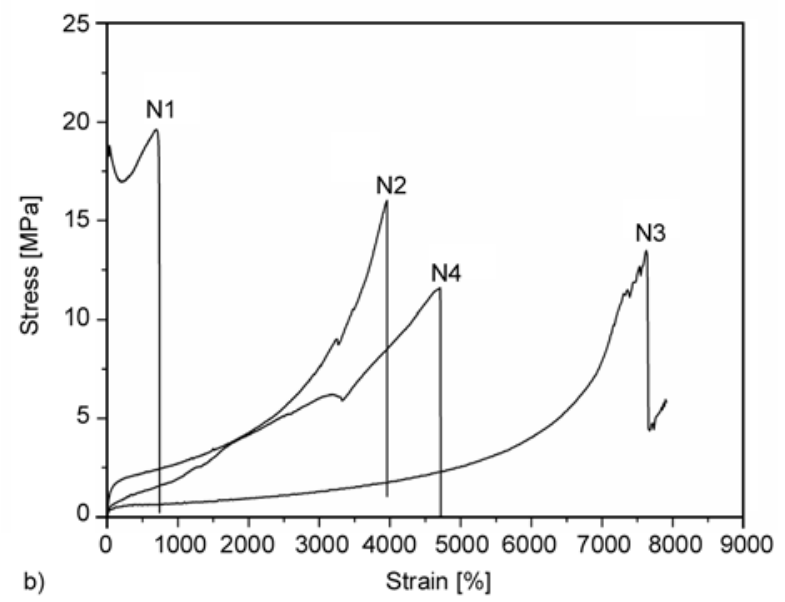

Figure 4. Stress-strain diagrams for: (a) the four BC and (b) the four NC 
for the four BC and their NC, respectively. From the mechanical point of view, it is not possible to compare the results obtained with the four copolymers as they show completely different nanostructuration behavior. The scope here is only to analyze the effects of the dispersion of $1 \mathrm{wt} \%(0.10 \mathrm{vol} \%)$ of nano-silver particles on each one of the polymeric materials used. According to different volume fractions of the hard and soft phases and resulting morphologies, the block copolymers and their nanocomposites show a variety of mechanical properties. As expected, due to the high content of PS in the L1 matrix ( $75 \mathrm{wt} \%)$, this block copolymer shows the highest tensile properties in term of modulus and strength, thus indicating its high resistance to plastic deformation. For L1 and N1, after reaching the yield point, strain softening prevails, leading to fracture. A macroscopic stress whitening of the specimen was observed during the tensile testing, which indicates the formation of microvoids in the sample thus confirming that, as reported in literature for SB diblock copolymers [44, 45], cavitation of the dispersed PB phase is followed by plastic deformation of the PS matrix via necking and drawing. However in L1 triblock copolymers, crazing of the PS matrix has been found thus indicating the preferential cavitation of the PS matrix. Cavitation in the PS phase is favored by termination of the copolymer chain ends in the styrene matrix [46]. Both SIS copolymers show higher elongation at break than the SBS ones. A first analysis of the mechanical tests indicates that the PI block is the main responsible of this behavior. In fact, the L3 SIS block copolymer, having the highest content of PI, was the one that showed the highest elongation at break.
The content of PS as also expected influences the mechanical properties. $\mathrm{L} 1$, the $\mathrm{BC}$ with the higher PS content, showed the highest elastic modulus but the smaller elongation at break. Even though the contents of PS in L2 and L4 block copolymers were very similar to each other, even L4, SIS, showed higher elongation at break due to the presence of PI block.

For each block copolymer-nanocomposite system studied the tensile modulus $E$, tensile strength, $\sigma$, and elongation at break, $\varepsilon$, are shown in Table 3 , also including the influence of surfactant on the tensile properties.

As expected, due to the high content of PS in the L1 matrix ( $75 \mathrm{wt} \%$ ), the block copolymer showed high modulus and strength, thus indicating the high resistance to plastic deformation. Nanocomposite N1, with 0.10 vol\% Ag nanoparticles treated with DT $($ Ag/DT weight ratio $=1)$, showed higher modulus, strength and elongation at break than the corresponding neat $\mathrm{BC}$, thus confirming that addition of adequate amount of surfactant leads to well-dispersed silver nanoparticles in the PS phase of the $\mathrm{BC}$ matrix. The influence of surfactant in the L1 matrix and the mechanical properties of nanocomposite without surfactant have also been analyzed. Comparing the results, the addition of surfactant to the neat matrix decreases the mechanical performance, as expected, as well as the nanocomposite obtained without surfactant shows mechanical properties lower than Ag/DT nanocomposite.

Higher values of the mechanical properties were also obtained for the other systems when $\mathrm{Ag} / \mathrm{DT}$ nanoparticles were added to the $\mathrm{BC}$ matrix. The behavior of L2-N2 system in terms of tensile modu-

Table 3. Tensile properties of the different studied systems

\begin{tabular}{|c|c|c|c|c|c|c|}
\hline Materials & $\begin{array}{c}\text { PS } \\
{[w t \%]}\end{array}$ & $\begin{array}{c}\mathbf{E} \\
{[\mathbf{M P a}]}\end{array}$ & $\begin{array}{c}\sigma \\
{[\mathrm{MPa}]}\end{array}$ & $\begin{array}{c}\varepsilon \\
{[\%]}\end{array}$ & $\begin{array}{c}\text { G-G equation } \\
\text { E [MPa] }\end{array}$ & $\begin{array}{c}\text { H-T model } \\
\text { E [MPa] }\end{array}$ \\
\hline L1 & \multirow{4}{*}{75} & $394 \pm 90$ & $20.6 \pm 2.0$ & $772 \pm 135$ & \multirow{4}{*}{514} & \multirow{4}{*}{498} \\
\hline $\mathrm{L} 1+\mathrm{DT}$ & & $333 \pm 95$ & $23.8 \pm 2.0$ & $805 \pm 105$ & & \\
\hline N1ws & & $372 \pm 90$ & $23.6 \pm 1.6$ & $980 \pm 110$ & & \\
\hline N1 & & $440 \pm 98$ & $24.6 \pm 1.8$ & $1021 \pm 128$ & & \\
\hline L2 & \multirow{4}{*}{31} & $13.6 \pm 2.2$ & $13.5 \pm 2.2$ & $3507 \pm 108$ & \multirow{4}{*}{18.6} & \multirow{4}{*}{16.2} \\
\hline $\mathrm{L} 2+\mathrm{DT}$ & & $13.5 \pm 2.1$ & $14.0 \pm 2.8$ & $3590 \pm 364$ & & \\
\hline N2ws & & $13.0 \pm 1.8$ & $14.2 \pm 2.1$ & $3695 \pm 305$ & & \\
\hline $\mathrm{N} 2$ & & $23.4 \pm 2.0$ & $15.5 \pm 1.8$ & $3818 \pm 87$ & & \\
\hline L3 & \multirow{2}{*}{15} & $1.3 \pm 0.2$ & $9.4 \pm 1.4$ & $6562 \pm 146$ & \multirow{2}{*}{-} & \multirow{2}{*}{-} \\
\hline N3 & & $2.0 \pm 0.6$ & $11.7 \pm 1.6$ & $7567 \pm 152$ & & \\
\hline L4 & \multirow{4}{*}{30} & $3.4 \pm 0.4$ & $8.7 \pm 0.9$ & $3756 \pm 651$ & \multirow{4}{*}{4.7} & \multirow{4}{*}{4.5} \\
\hline L4+DT & & $2.8 \pm 0.8$ & $7.6 \pm 0.9$ & $3891 \pm 453$ & & \\
\hline N4ws & & $4.0 \pm 0.5$ & $4.6 \pm 0.9$ & $3788 \pm 756$ & & \\
\hline N4 & & $4.5 \pm 0.3$ & $9.7 \pm 0.7$ & $4718 \pm 400$ & & \\
\hline
\end{tabular}


lus, strength and elongation at break is also reported in Table 3. The Ag/DT/L2 nanocomposite showed the higher value for each mechanical property. N2 presented double tensile modulus and higher tensile strength with respect to neat L2 and also high elongation at break, around $3800 \%$. It is worth to note that in this case even for the nanocomposite obtained without surfactant it was possible to obtain higher mechanical properties with respect to neat L2, due to the well-ordered morphology that can be obtained, as reported below.

The mechanical response of L3-N3 system is shown in Table 3. In this case the influence of surfactant has not been reported since a very low value of tensile modulus was obtained. It is worth to note that, even the L3 material showed very low modulus, the elongation at break was the largest of the materials studied, around $6500 \%$, due to the high content of PI. In the case of the nanocomposite, the characteristic elongation at break increased up to a value of more than $7000 \%$, indicating a good interfacial adhesion between the nanoparticles and the matrix.

Finally the mechanical properties for L4-N4 are reported also on Table 3. Also in this case, higher mechanical properties were obtained for the nanocomposite based on $\mathrm{BC}$ matrix and coated $\mathrm{Ag} / \mathrm{DT}$ nanoparticles. Furthermore, it can be pointed out that in the case of nanocomposite without surfactant, the mechanical properties were lower, thus indicating agglomeration of nanoparticles. Basically, taking into account the lower tensile strength obtained for the nanocomposite without surfactant with respect to neat L4, agglomerated Ag nanoparticles act as 'defects', thus worsening the mechanical performance of the nanocomposites.

Moreover, comparing the SIS block copolymer L4, with the SBS containing similar amount of PS, that is L2, it can be noted that the tensile strength of the $\mathrm{Ag} / \mathrm{SBS}$ nanocomposite is not lower than the tensile strength obtained for neat $\mathrm{BC}$ matrix, as occurred in case of L4-N4. This fact can be explained taking into account the morphology of the NC obtained without surfactant, as shown below. Figure 5a presents in fact, the morphology obtained for uncoated $\mathrm{Ag} / \mathrm{L} 1$ nanocomposites. No aggregation was observed due to good dispersion of $\mathrm{Ag}$ nanoparticles in the SBS matrix. For $\mathrm{Ag} / \mathrm{L} 2$ nanocomposite a cylindrical morphology can be still detected (Figure 5b). The good confinement of Ag nanoparticles in the SBS matrix justifies the higher value in terms of tensile properties obtained respect to neat L2. On the contrary, for $\mathrm{Ag} / \mathrm{L} 4$ system, (Figure 5c) when untreated Ag nanoparticles were added to the matrix, no self-assembly of the $\mathrm{BC}$ matrix was obtained. Taking into account the agglomeration observed in Ag/DT/L3 samples, it was decided to neglect the analysis of the morphology of the L3 nanocomposite, without surfactant.

Finally, the tensile properties of the different studied systems have been summarized and compared with the theoretical values obtained from the empirical models represented by the Guth and Gold (G-G) equation [31-32] and the Halpin-Tsai (H-T) model [33-35] for the tensile modulus of composite materials. Guth and Gold introduced a quadratic term on the Smallwood-Einstein equation to explain the reinforcing effect of fillers on elastomeric matrices taking into account the interactions between fillers, as shown in Equation (3):

$E_{\mathrm{c}}=E_{\mathrm{m}}\left[1+2.5 \phi_{\mathrm{f}}+14.1 \phi_{\mathrm{f}}^{2}\right]$

where $E_{\mathrm{c}}$ is the tensile modulus of the composite, $E_{\mathrm{m}}$ is the tensile modulus of the matrix and $\phi_{\mathrm{f}}$ is the volume fraction of filler. This equation is only applicable to elastomers filled with an amount of spherical filler lower than $10 \mathrm{vol} \%$. Besides, the HalpinTsai model, based on the properties of the pure components and the morphology of the final composite, is also widely used to estimate reinforcement effects of fillers in composites. This model, that also shows good results when applied to nanocomposites [45], is expressed by Equation (4):

$E=E_{\mathrm{m}} \cdot \frac{1+\zeta \eta \phi_{\mathrm{f}}}{1-\eta \phi_{\mathrm{f}}}$

where $\zeta$ is a shape factor parameter dependent upon filler geometry and loading direction ( $\zeta$ can be considered equal to 2 for spherical nanoparticles [46]) and $\eta$ is given by Equation (5):

$\eta=\frac{\frac{E_{\mathrm{f}}}{E_{\mathrm{m}}}-1}{\frac{E_{\mathrm{f}}}{E_{\mathrm{m}}}+\zeta}$

An assumption inherent in all of these theories is that each component acts independently of the other. In our case it is worth to consider also the surfactant effect. So, to calculate the theoretical tensile modu- 


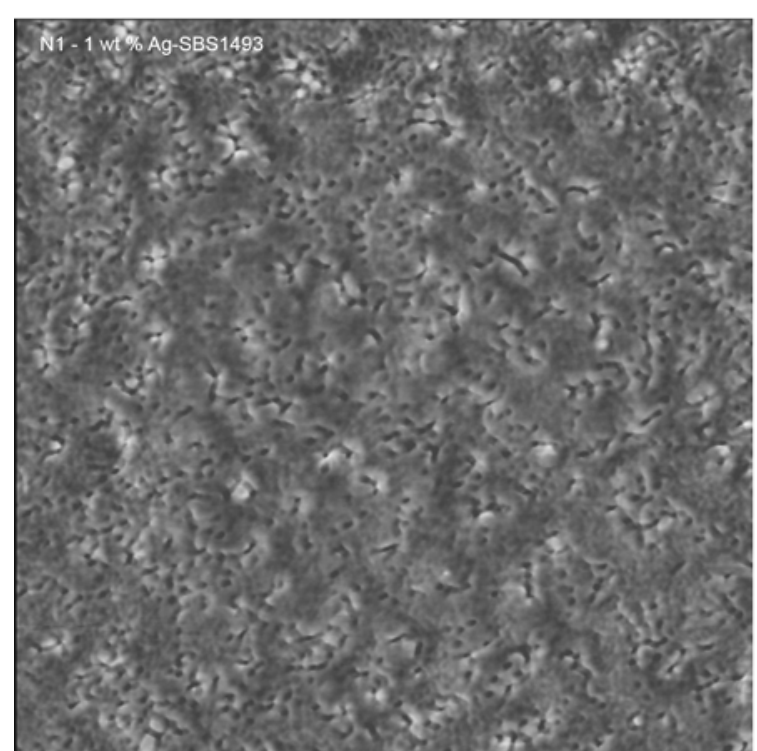

0

a)

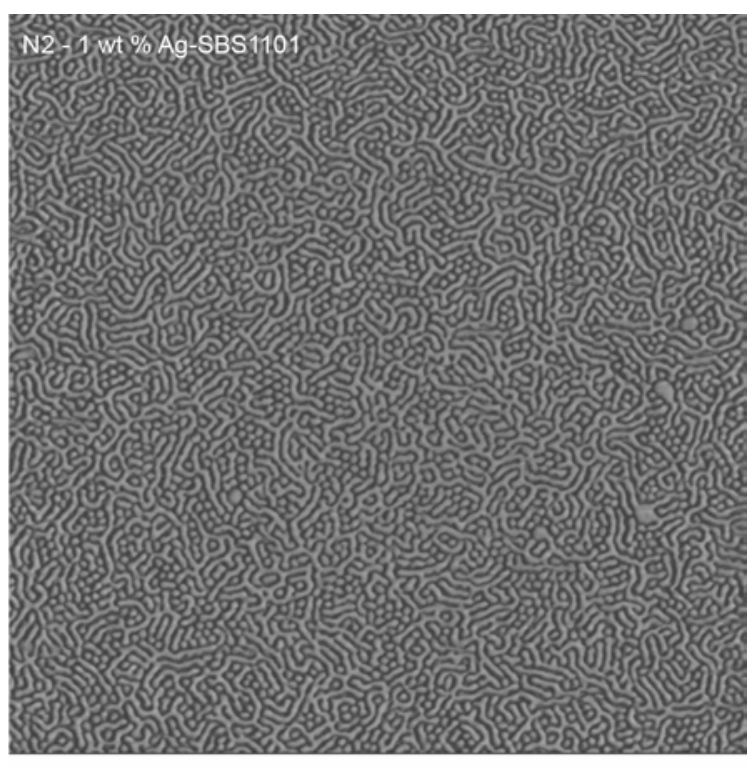

b)

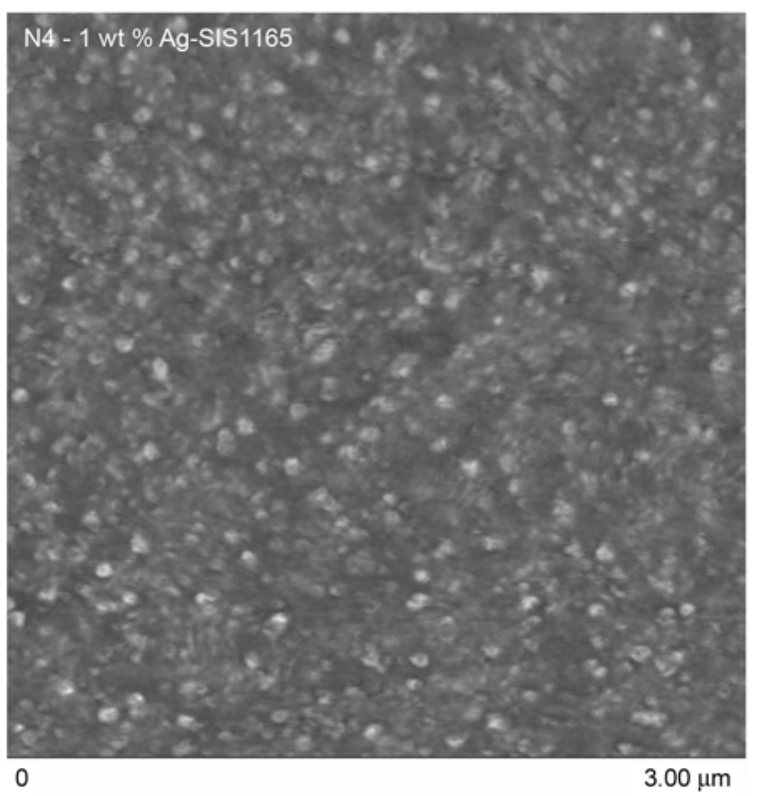

c)

Figure 5. TM-AFM height and phase images for: (a) $\mathrm{Ag} / \mathrm{L} 1$, (b) $\mathrm{Ag} / \mathrm{L} 2$, and (c) $\mathrm{Ag} / \mathrm{L} 4$ films

lus of the final nanocomposite, first, the rule of mixtures has been taken into account to calculate the effect of surfactant on the matrix tensile modulus [46], as shown in Equation (6):

$E_{\mathrm{DT} / \mathrm{BC}}=\phi_{\mathrm{DT}} E_{\mathrm{DT}}+\left(1-\phi_{\mathrm{DT}}\right) E_{\mathrm{BC}}$

Thus the value obtained for tensile modulus, $E_{\mathrm{DT} / \mathrm{BC}}$, can be considered as the matrix tensile modulus in the Guth and Gold and Halpin-Tsai models to calculate the nanocomposite tensile modulus reported in Table 3. The highest value of tensile modulus and tensile strength was found for the first block copolymer, L1, confirming that the higher amount of PS influences the mechanical properties. Furthermore, this $\mathrm{BC}$ is the only one star block copolymer, and, as reported in literature, star block copolymers show higher mechanical properties than linear ones. Additionally, for the same wt $\%$ of PS, SBS block copolymers showed higher tensile properties than the SIS ones in terms of tensile modulus and tensile strength. On the other hand, SIS block copolymers showed higher elongation at break than SBS ones. The lower was the content of PS in the $\mathrm{BC}$ matrix the higher was the value of elongation at break. Interesting is to note that, even for L3, characterized by the lowest tensile modulus, the tensile strength 
values were comparable with those obtained for the other systems, such as L2 or L3, thus confirming the well confinement of the $\mathrm{Ag}$ nanoparticles in the PS block of the block copolymer matrix and their good adhesion.

Regarding the theoretical tensile modulus, it is worth to note that in case of L3, due to its low value, the empirical model is not applicable. Whereas for the other systems the Guth and Gold and HalpinTsai models have shown to be able to predict the tensile modulus of the studied nanocomposites. In fact, the theoretical values are quite similar to the experimental ones, even considering the effects of many factors not considered by the simple Guth and Gold model and the no ideality of Halpin-Tsai hypothesis.

\section{Conclusions}

The macroscopic response in terms of mechanical properties of metallopolymer films based on $\mathrm{BC}$ matrix and silver nanoparticles has been analyzed. To obtain well dispersed silver nanoparticles in SBS or SIS matrices dodecanethiol was used as surfactant with a weight ratio $\mathrm{Ag} / \mathrm{DT}$ of 1 . From the mechanical point of view, the good confinement of $\mathrm{Ag}$ nanoparticles in the PS phase leads to higher tensile properties in terms of tensile modulus, tensile strength and elongation at break than neat $\mathrm{BC}$ matrices. When surfactant was not used, the increase in the mechanical properties values was not so significant, thus indicating that aggregation of $\mathrm{Ag}$ nanoparticles can act as defects into the $\mathrm{BC}$ matrix. As expected, the amount of PS influences the mechanical response of the nanocomposites as well as the rheological one. Indeed L1-N1, the system with higher content of PS showed the highest tensile strength and tensile modulus and, on the other hand, this system presented the lowest elongation at break. Finally, it should be pointed out that L3-N3 showed an interesting behavior when compared to the others. Even if this BC is characterized by the lowest content of PS and its tensile modulus is very low, the obtained tensile strength was comparable with that for the other systems while the elongation at break was the highest, thus confirming that the soft block of this $\mathrm{BC}$, isoprene, is responsible of the peculiar elastic behavior to this material and of its nanocomposite.

\section{References}

[1] Krausch G., Magerle R.: Nanostructured thin films via self-assembly of block copolymers. Advanced Materials, 14, 1579-1583 (2002).

DOI: $10.1002 / 1521-4095(20021104) 14: 21<1579:$ : AID-ADMA1579>3.0.CO;2-6

[2] Hamley I. W.: Nanostructure fabrication using block copolymers. Nanotechnology, 14, R39-R54 (2003).

DOI: $10.1088 / 0957-4484 / 14 / 10 / 201$

[3] Sangermano M., Priola A., Kortaberria G., Jimeno A., Garcia I., Mondragon I. Rizza G.: Photopolymerization of epoxy coatings containing iron-oxide nanoparticles. Macromolecular Materials and Engineering, 292, 956-961 (2007).

DOI: $10.1002 /$ mame.200700093

[4] Lazzari M., López-Quintela A.: Block copolymers as a tool for nanomaterial fabrication. Advanced Materials, 15, 1583-1594 (2003). DOI: $10.1002 / \mathrm{adma} .200300382$

[5] Serrano E., Tercjak A., Kortaberria G., Pomposo J. A., Mecerreyes D., Zafeiropoulos N. E., Stamm M., Mondragon I.: Nanostructured thermosetting systems by modification with epoxidized styrene-butadiene star block copolymers. Effect of epoxidation degree. Macromolecules, 39, 2254-2261 (2006).

DOI: $10.1021 / \mathrm{ma} 0515477$

[6] Bates F. S., Fredrickson G. H.: Block copolymer thermodynamics: Theory and experiment. Annual Review of Physical Chemistry, 41, 525-557 (1990). DOI: 10.1146/annurev.pc.41.100190.002521

[7] Huang C-I., Lodge T. P.: Self-consistent calculations of block copolymer solution phase behavior. Macromolecules, 31, 3556-3565 (1998).

DOI: $10.1021 / \mathrm{ma980007p}$

[8] Matsen M. W., Bates F. S.: Unifying weak- and strongsegregation block copolymer theories. Macromolecules, 29, 1091-1098 (1996).

DOI: $10.1021 / \mathrm{ma} 951138 \mathrm{i}$

[9] Matsen M. W., Bates F. S.: Conformationally asymmetric block copolymers. Journal of Polymer Science Part B: Polymer Physics, 35, 945-952 (1997).

DOI: 10.1002/(SICI)1099-0488(19970430)35:6<945:: AID-POLB9>3.0.CO;2-G

[10] Tercjak A., Gutierrez J., Peponi L., Rueda L., Mondragon I.: Arrangement of conductive $\mathrm{TiO}_{2}$ nanoparticles in hybrid inorganic/organic thermosetting materials using liquid crystal. Macromolecules, 42, 33863390 (2009). DOI: $10.1021 / \mathrm{ma} 8022553$

[11] Park C., Yoon J., Thomas E. L.: Enabling nanotechnology with self assembled block copolymer patterns. Polymer, 44, 6725-6760 (2003). DOI: $10.1016 /$ j.polymer.2003.08.011

[12] Bates F. S., Fredrickson G. H.: Block copolymers Designer soft materials. Physics Today, 52, 32-38 (1999).

DOI: $10.1063 / 1.882522$ 
[13] Ott H., Abetz V., Alstadt V.: Morphological studies of poly(styrene)-block-poly(ethylene-co-butylene)-blockpoly(methyl methacrylate) in the composition region of the 'knitting pattern' morphology. Macromolecules, 34, 2121-2128 (2001).

DOI: $10.1021 / \mathrm{ma} 0017079$

[14] Jeson H. S., Rameshwaram J. K., Kim G., Weinkauf D. H.: Characterization of polyisoprene-clay nanocomposites prepared by solution blending. Polymer, 44, 5749-5758 (2003).

DOI: $10.1016 / \mathrm{S} 0032-3861(03) 00466-\mathrm{X}$

[15] Incarnato L., Scarfato P., Scatteia L., Acierno D.: Rheological behavior of new melt compounded copolyamide nanocomposites. Polymer, 45, 3487-3496 (2004).

DOI: $10.1016 /$ j.polymer.2004.03.005

[16] Raghu P., Nere C. K., Jagtap R. N.: Effect of styreneisoprene-styrene, styrene-butadiene-styrene, and styrenebutadiene-rubber on the mechanical, thermal, rheological, and morphological properties of polypropylene/ polystyrene blends. Journal of Applied Polymer Science, 88, 266-277 (2003).

DOI: 10.1002 app.11677

[17] Buzdugan E., Ghioca P., Stribeck N., Badea E. G., Serban S., Iovu M. C.: Mechanical properties of some brominated styrene-diene block copolymers. European Polymer Journal, 34, 1531-1537 (1998).

DOI: 10.1016/S0014-3057(98)00004-4

[18] Peponi L., Tercjak A., Torre L., Kenny J. M., Mondragon I.: Surfactant effects on morphology-properties relationships of silver-poly(styrene- $b$-isoprene- $b$-styrene) block copolymer nanocomposites. Journal of Nanoscience and Nanotechnology, 9, 2128-2139 (2009).

DOI: $10.1166 /$ jnn.2009.437

[19] Fan F. R. F., Bard A. J.: Chemical, electrochemical, gravimetric, and microscopic studies on antimicrobial silver films. Journal of Physical Chemistry B, 106, 279-287 (2002).

DOI: $10.1021 / \mathrm{jp} 012548 \mathrm{~d}$

[20] Hutter E., Fendler J. H.: Exploitation of localized surface plasmon resonance. Advanced Materials, 16, 1685-1706 (2004).

DOI: 10.1002/adma.200400271

[21] Bockstaller M. R., Mickiewicz R. A., Thomas E. L.: Block copolymer nanocomposites: Perspectives for tailored functional materials. Advanced Materials, 17, 1331-1349 (2005).

DOI: $10.1002 / \mathrm{adma} .200500167$

[22] Thompson R. B., Ginzburg V. V., Matsen M. W., Balazs A. C.: Predicting the mesophases of copolymernanoparticle composites. Science, 292, 2469-2472 (2001).

DOI: $10.1126 /$ science. 1060585

[23] Niu S. J., Saraf R. F.: Selective assembly of nanoparticles on block copolymer by surface modification. Nanotechnology, 18, 125607/1-125607/4 (2007). DOI: $\underline{10.1088 / 0957-4484 / 18 / 12 / 125607}$
[24] Bockstaller M. R., Lapetnikov Y., Margel S., Thomas E. L.: Size-selective organization of enthalpic compatibilized nanocrystals in ternary block copolymer/particle mixtures. Journal of the American Chemical Society, 125, 5276-5277 (2003).

DOI: $10.1021 / \mathrm{ja034523t}$

[25] Darling S. B., Yufa N. A., Cisse A. L., Bader S. D., Sibener S. J.: Self-organization of FePt nanoparticles on photochemically modified diblock copolymer templates. Advanced Materials, 17, 2446-2450 (2005). DOI: $10.1002 / \mathrm{adma} .200500960$

[26] Huh J., Ginzburg V. V., Balazs A. C.: Thermodynamic behavior of particle/diblock copolymer mixtures: Simulation and theory. Macromolecules, 33, 8085-8096 (2000).

DOI: $10.1021 / \mathrm{ma} 000708 \mathrm{y}$

[27] Peponi L., Tercjak A., Gutierrez J., Stadler H., Torre L., Kenny J. M., Mondragon I.: Self-assembling of SBS block copolymers as templates for conductive silver nanocomposites. Macromolecular Materials and Engineering, 293, 568-573 (2008).

DOI: $10.1002 /$ mame.200800033

[28] Peponi L., Tercjak A., Torre L., Kenny J. M., Mondragon I.: Influence of the amount of silver nanoparticles in the properties of nanocomposites based on poly(styrene- $b$-isoprene- $b$-styrene) and poly(styrene$b$-butadiene- $b$-styrene) block copolymer matrix. Journal of Nanostructured Polymer Nanocomposites, 4, 76-83 (2008).

[29] Peponi L., Tercjak A., Torre L., Kenny J. M., Mondragon I.: Morphological analysis of self-assembled SIS block copolymer matrices containing silver nanoparticles. Composite Science and Technology, 68, 1631-1638 (2008).

DOI: 10.1016/j.compscitech.2008.02.032

[30] Lee J. Y., Thompson R. B., Jasnow D., Balazs A. C.: Effect of nanoscopic particles on the mesophase structure of diblock copolymers. Macromolecules, 35, 4855-4858 (2002).

DOI: $10.1021 / \mathrm{ma} 0200266$

[31] Wu Y-P., Jia Q-X., Yu D-S., Zhang L-Q.: Modeling Young's modulus of rubber-clay nanocomposites using composite theories. Polymer Testing, 23, 903-909 (2004).

DOI: $10.1016 /$ j.polymertesting.2004.05.004

[32] Guth E., Gold O.: On the hydrodynamic theory of the viscosity of suspensions. Physical Review, 53, 322 (1938).

[33] Halpin Affdl J. C., Kardos J. L.: The Halpin-Tsai equations: A review. Polymer Engineering and Science, 16, 344-352 (1976). DOI: $10.1002 /$ pen.760160512

[34] Camacho C. W., Tucker III C. L., Yalvaç S., McGee R. L.: Stiffness and thermal expansion predictions for hybrid short fiber composites. Polymer Composites, 11, 229-239 (1990). DOI: $10.1002 /$ pc. 750110406 
[35] Miyagawa H., Mase T., Sato C., Drown E., Drzal L. T., Ikegami K.: Comparison of experimental and theoretical transverse elastic modulus of carbon fibers. Carbon, 44, 2002-2008 (2006).

DOI: $10.1016 / \mathrm{j}$.carbon.2006.01.026

[36] Han C. D., Kim J., Kim J. K.: Determination of the order-disorder transition temperature of block copolymers. Macromolecules, 22, 383-394 (1989).

DOI: $10.1021 / \mathrm{ma} 00191 \mathrm{a} 071$

[37] Greer J. R., Street R. A.: Mechanical characterization of solution-derived nanoparticle silver ink thin films. Journal of Applied Physics, 101, 103529/1-103529/5 (2007).

DOI: $10.1063 / 1.2735404$

[38] Brandrup J., Immergut E. H.: Polymer handbook. Wiley, New York (1989).

[39] Van Krevelen D. W.: Properties of polymers. Elsevier, Amsterdam (1990).

[40] Floudas G., Steffen W., Hadjichristidis N.: Order-disorder transition in a poly(styrene- $b$-isoprene) diblock copolymer at hypersonic frequencies. Europhysics Letters, 44, 37-43 (1998). DOI: $10.1209 / \mathrm{epl} / \mathrm{i} 1998-00431-5$

[41] Hamersky M. W., Tirell M., Lodge T. P.: Self-diffusion of a polystyrene-polyisoprene block copolymer. Journal of Polymer Science Part B: Polymer Physics, 34, 2899-2909 (1996).

DOI: $10.1002 /($ SICI) 1099-0488(199612)34:17<2899:: AID-POLB4>3.0.CO;2-M
[42] Lee K. M., Han C. D.: Linear dynamic viscoelastic properties of functionalized block copolymer/organoclay nanocomposites. Macromolecules, 36, 804-815 (2003).

DOI: $10.1021 / \mathrm{ma} 020816 \mathrm{f}$

[43] García I., Tercjak A., Rueda L., Mondragon I.: Selfassembled nanomaterials using magnetic nanoparticles modified with polystyrene brushes and poly (styrene- $b$-butadiene- $b$-styrene). Macromolecules, 41, 9295-9298 (2008).

DOI: $10.1021 / \mathrm{ma} 801701 \mathrm{k}$

[44] Weidisch R., Michler G. H., Arnold M., Fischer H.: Mechanical properties of weakly segregated block copolymers - Part IV - Influence of chain architecture and miscibility on tensile properties of block copolymers. Journal of Materials Science, 35, 1257-1268 (2000). DOI: 10.1023/A:1004757008254

[45] Miller A. C., Bennet R. D., Hammond P. T., Irvine D. J., Cohen R. E.: Functional nanocavity arrays via amphiphilic block copolymer thin films. Macromolecules, 41, 1739-1744 (2008). DOI: $10.1021 / \mathrm{ma} 7019418$

[46] Fornes T. D., Paul D. R.: Modeling properties of nylon 6/ clay nanocomposites using composite theories. Polymer, 44, 4993-5013 (2003). DOI: $10.1016 / \mathrm{S} 0032-3861(03) 00471-3$ 